\title{
DYNAMIC PROGRAMMING, AN APPROACH FOR ANALYSING COMPETITION STRATEGIES
}

\section{T. PentikÄinen*}

Stochastic-dynamic programming provides a technique for forecasting limits within which the insurance business will flow by a prefixed probability. The future development depends, among numerous other things, on management strategies, especially resources, which are planned for allocation in the acquisition of new business and for competition. This technique can be used to analyse different market situations. Various competitive measures and eventual counteractions by competitors can be assumed and simulated for the purpose. In this way the consequences of different strategies can be studied in order to find the most appropriate one. Our approach is similar to the well-known business games where teams play business in a simulated market. The idea of applying dynamic programming to business games was suggested by Esa Hovinen (discussion at the Astin Colloquium in Washington in 1977).

\section{STOCHASTIC-DYNAMIC PROGRAMMING}

Stochastic-dynamic programming is a technique for making prognoses for the future development of the insurance business. When the initial state is known and necessary characteristics such as the volume of premiums, claim size distributions, expected number of claims, yield of interest, probable growth of

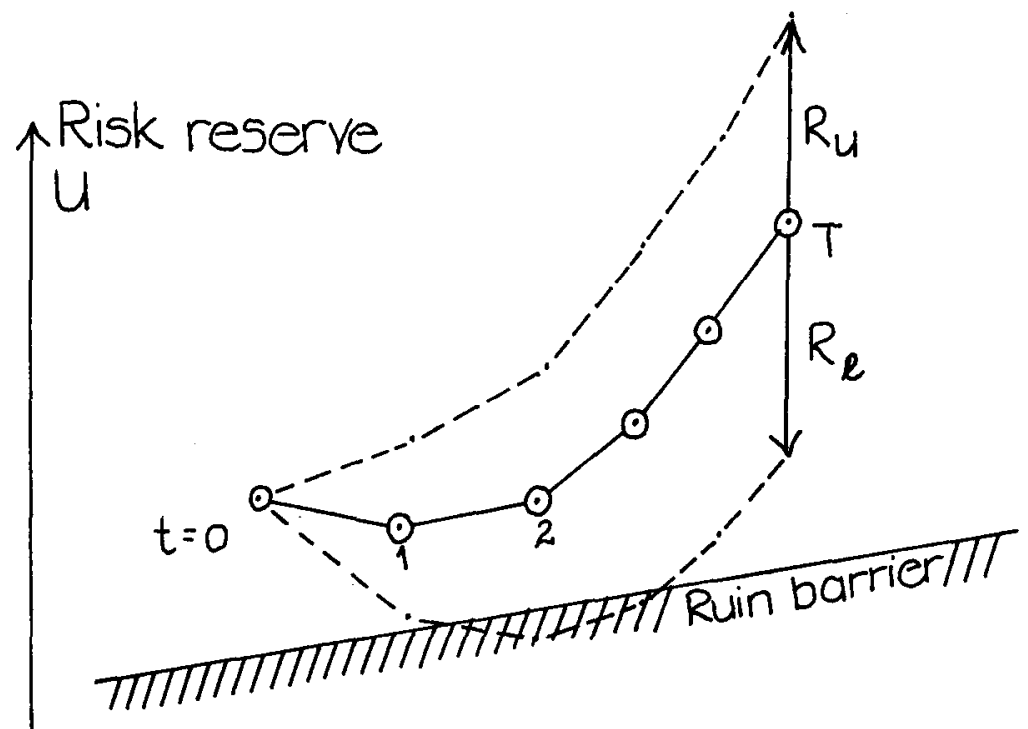

Fig. 1.

Premiums

* Presented at the 14th ASTIN Colloquium, Taormina, October 1978. 
the business, margins needed for operational cost, etc. are given or assumed, then it is possible step by step for future points in time $t=1,2, \ldots, T$ to make a prognosis for state variables such as premium volume $P$, risk reserve (free reserves) $U$, etc. Due to the stochastic character of the method, a distribution of each state variable is obtained for each time $t$. The probability of ruin is also obtained as a byproduct. Fig. 1 illustrates the idea. The mean value of the premium volume $P$ and risk reserve $U$ is calculated for $t=1,2, \ldots, T$. In addition, the limits of the stochastic flow of the business are estimated (upper limit $R_{u}$ and lower limit $R_{l}$ ). When a ruin barrier is defined, the probability of ruin is obtained as a byproduct.

The flow of business and also the security limits $R$ depend on the management strategy which the company is assumed to follow. Competition, especially, can be an important factor.

The dynamic programming approach is referred to in detail by the author in the papers listed in the bibliography.

\section{BUSINESS MODELS FOR COMPETITIVE MEASURES}

For model building it is necessary to know how the insurance market reacts to such competitive measures as changes in premiums, sales promotion efforts, etc. Obviously circumstances vary a great deal in different countries and even within a country, e.g. concerning the branch of insurance, perhaps concerning particular groups of insurance and clients, etc. It is well known that the degree of market saturation is one essential factor. The theory and technique for constructing market reaction models are developed for industrial and commercial practice. A good review is given by KOTLER (1975). These general approaches are clearly also applicable to insurance. Of course market reactions are mainly phenomena that can be ascertained only by collecting experience in real situations.

Two examples of the market reactions of the Finnish third party motor and motor vehicle insurance business are given in figs. 2 and 3. Company 1 reduced the premiums for third party motor insurance (fig. 2) by about 8 per cent and those for motor vehicle business (fig. 3 ) by about 15 per cent. The reduction was valid for one year, 1973-1974. The other companies followed suit, reducing motor vehicle (but not third party) rates to the same extent. Following this the companies again agreed on a joint level for rates. The reaction in the market share percentages can be clearly seen. Thanks to their different special groups of clients companies 3 and 5 were immune to the competitive action taken by company 1. Company 1 also carried out an advertising campaign whereas company 2 took some rationalisation measures which obviously temporarily reduced the volume of sales. Hence the changes in market shares were also due to reasons other than different rates, but this situation will not be analysed here. The reduction in third party motor rates was reflected in the market shares for motor vehicle insurance, too, even if the rates were not different. 


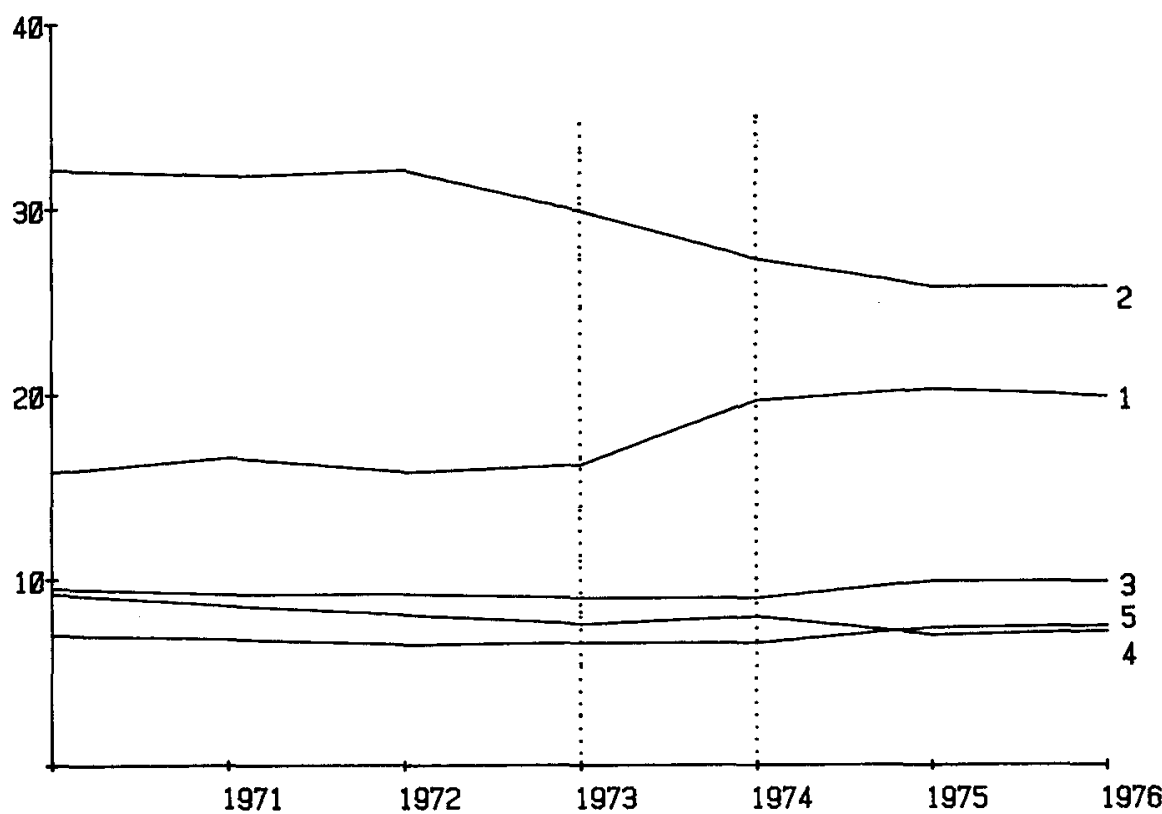

Fig. 2. Third party motor insurance. Trend in market shares of the five largest companies as percentages of the whole market.

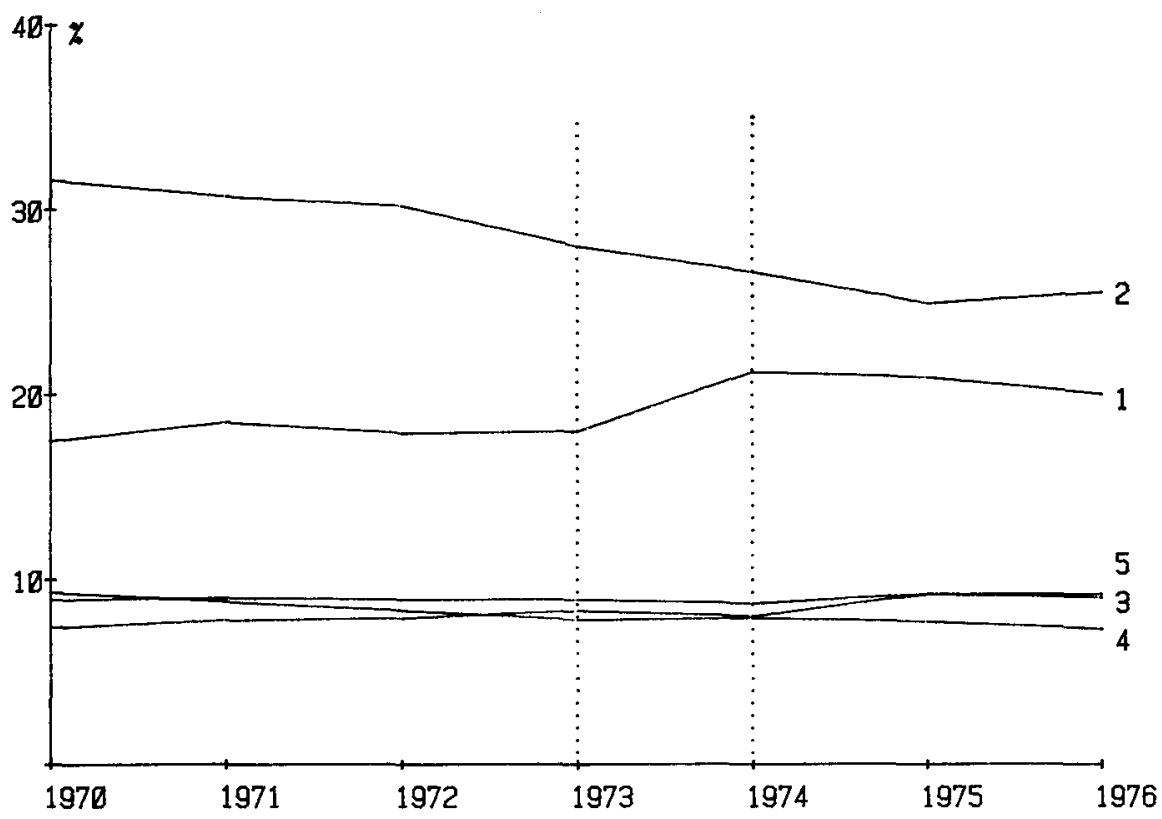

Fig. 3. Motor vehicle insurance. Market shares as in fig. 2. 
The return from competitive measures is described by what is called a sales response function. The return in our case is an increase in premium volume. The problems of how to find appropriate sales response functions will not be discussed here. A derivation of this kind is a standard excercise in economic theory (cf. KotLen 1975). Our purpose is only to show how the dynamic programming technique can function if the sales response function and all other necessary initial facts are known.

To provide a simple illustration we assume that the sales response function is of the simple exponential form

$$
P(t)=P(t-1) \cdot(1+g) \cdot(1-\pi(t))^{-p}
$$

$P(t)$ is the premium volume for year $t, g$ is the rate of natural growth of the business (level expected without competitive action) and $\pi(t)$ is the relative decrease in the premium rates, assumed to have been made in year $t$ as a competitive action. $p$ is the coefficient of elasticity (empirical data). The formula is a simplified version of formula (14) discussed in my paper (1978).

By partially differentiating formula (1) we obtain

$$
\frac{\Delta P_{\pi}}{P} \approx p \pi
$$

The relative sales response, i.e. the increase in premium volume due to $\pi$, is proportional to $\pi$, elasticity $p$ being a proportionality coefficient.

In fact a reduction $\pi$ in the premium rates has a double effect. On the one hand it promotes the sale of new business according to formula (2). On the other hand an amount $\pi P$ is lost from the premium income (and at the same time, from the profit margin). This term $\pi P$ should be subtracted from (1) to get the actual premium income. It is, however, convenient for the computation to use the unreduced premium volume $P$ obtained from (1) and take the reduction $\pi P$ into account as a loss of profit, as was done in the formulae represented in the paper mentioned above. This unreduced premium best demonstrates the effect of the competitive action. For this reason we have taken it as the variable $P$ in the following figures. Because the competitive reductions $\pi(t)$ will be assumed to be only temporary in our examples, the final values $P(T)$ equal the actual premium incomes even if in the intermediate years the actual premium incomes deviate from $P$. Unreduced $P$ also best represents the actual clientele.

From fig. 2 a value for $p$ is got. It seems to be of the order of 2 . We assume in the following $p=1.5$.

It is obvious that the exponential sales response function is applicable only to an open market where saturation is not imminent. As a short time reaction it may also be more generally applicable, but if the premium reduction has a duration of several years, the sales function is probably more of the $S$ form, as 
Kotler claims. We omit this kind of analysis and use the simple form (1), because here we are only demonstrating the dynamic programming approach.

We have also simplified the example by assuming that the competitive reduction of premiums concerns the whole business of the company. Actually, of course, most non-life companies have many insurance branches and competition can be restricted only to part of the business. In principle the approach is also applicable to more complicated cases, but then the business must be divided into subsections, e.g. according to insurance branch. A simple example along this line was given by the author (1975).

Another simplification is the assumption that a premium reduction is the only competitive action. This is probably generally supported e.g. by an advertising campaign and other sales promotion efforts. Extension of the sales response function for this can also be found in the author's paper (1978).

\section{A MUlti-unit COMPETITION MODEL}

We are now going to deal with a market in which the leading companies are $C_{1}, C_{2}$ and $C_{3}$. In addition, a number of smaller companies operate in the same market. We assume that the latter have a joint tariff association and follow the same rates; hence we can "unite" them as a "fourth company", $C_{4}$, in our model.

In order to apply the model it is necessary to know, at least approximately, the initial state and a great number of parameters for each of the companies involved, in this case also as concerns competitors. In practice this may be difficult. However, at least in some countries the annual reports of the companies, the official statistics and other papers available can probably make it possible for a skilful analyst to gather numerous pieces of information and compile from them a picture on the state and resources of the competitors, at least when the analysis is continued for several years (collecting this kind of information may be a practice in many companies).

We apply the same formula (1) for all companies $C_{i}, i=1,2,3,4$. The premium reductions $\pi_{i}(t)$ which company $i$ applies in year $t$ are the decision variables of the model. Different competitive strategies are obtained by taking different values for these variables, i.e. the matrix $\left(\pi_{i}(t)\right)$ where $i=1,2,3,4$ and $t=1,2, \ldots, T$, defines the total competitive strategy mixture.

The competitive effect can be expected to be proportional to the difference in premiums between companies, i.e. the cheaper the premiums a company $i$ applies compared with the average level of the market, the more new business it can expect. Hence formula (1) must be amended by introducing the relative differences in the level of premiums as follows. The weighted average level of the premium reduction is

$$
\bar{\pi}(t)=\frac{1}{P(t)} \sum_{i} P_{i}(t) \pi_{i}(t)
$$


where $P(t)=\sum P_{i}(t)=$ the total volume of premiums on the market. Then the relative premium reduction for company $i$ is

$$
\pi_{i}^{\prime}(t)=\pi_{i}(t)-\bar{\pi}(t)
$$

This variable will replace $\pi$ in formula (1). The loss of profit owing to the premium reduction must always be calculated on the basis of the absolute reduction $\pi$ compared with the initial level $\pi=0$. All companies have the same initial rate, i.e. $\pi_{i}(0)=0$. Hence, if all companies reduce their premiums by the same relative amount $\pi_{i}=\bar{\pi}$, nobody will reap any benefit in the form of increased premium volume but, of course, all companies will suffer loss of profit due to reduced premiums. With some calculation formulae (2)-(4) show that generally changes in premiums $\Delta P_{i}(t)$ caused by any combination of variables $\pi_{i}(t)$ are

$$
\sum_{i} \Delta P_{i} \approx 0
$$

This equation, where $\Delta P$ is again the change in unreduced premium income, is only approximately valid, because (2) is also an approximation obtained by a simple differentiation. A sales response of this type applies to saturated markets where competitive action mainly causes only an increase in market shares at the expense of the competitors.

In terms of the theory of games, we are dealing with an $n$-person multiperiod zero-sum game in an oligopolistic market. The model can be extended to elastic markets, where a premium reduction increases the total demand for insurance. A factor $(1-\bar{\pi}(t))^{-p^{\prime}}$ must be attached to formula (1) for the purpose. This will be done in fig. 8 .

Applying the formulae given above and those given in more detail by the author (1978), it is possible to compute the business flow for different mixed strategies $\left(\pi_{i}(t)\right)(i=1,2 \ldots ; t=1,2, \ldots, T)$. The model can be programmed for a computer. The probability of ruin, the profits and losses and the final state of each company can be obtained as output for any strategy assumed. A good review can be obtained by arranging the main state variables, volume of premiums $P$ and risk reserve $U$ on a $P, U$-plane as in fig. 4 . At the final point the number of the strategy is assigned (in fig. 4 only two strategies were applied). In our example $T=5$ years. $C_{i}$ indicates the company $i$. The lines (solid for company 1 and dotted for the others) from the initial point $P_{i}(\mathrm{o})$, $U_{i}(0)$ to the final point $P_{i}(T), U_{i}(T)$ show the flow of the business as in fig. 1 . A change $\pi_{i}(t-1) \rightarrow \pi_{i}(t)$ gives rise to a deviation from the normal flow $\left(\left(\pi_{i}(t)\right)=0\right)$ and also affects the other companies due to $(5)$.

We are now ready to test the model by analysing the efforts and consequences of different strategies.

Strategy I was the "neutral" one, where no premium reductions were 


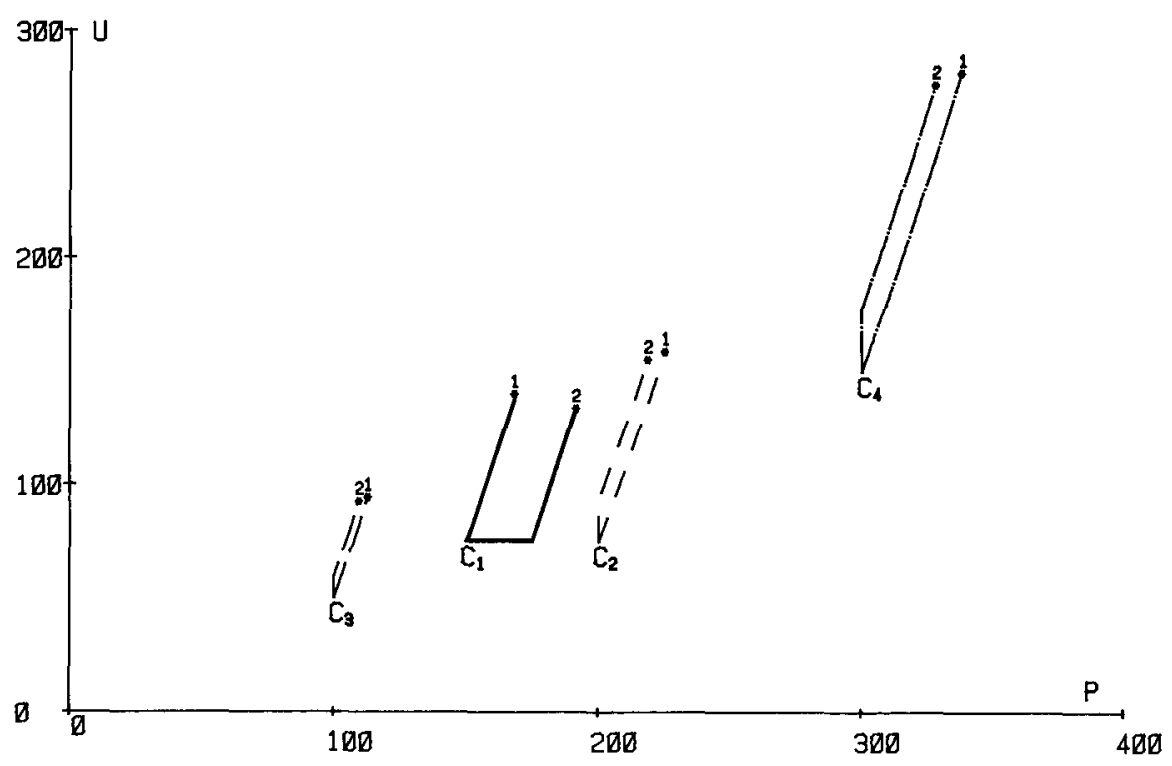

Fig. 4. Results obtained by different strategies. Units of $P$ and $U$ are some convenient multiple of the currency unit of the country (in our example $10^{6}$ Fmk). Formulae and data as in example 1 in the author's paper (1978).

applied, i.e. all $\pi_{i}(t)=0$. Due to the normal growth factor $g$ in formula (1) and an assumed safety loading all companies get an increase in both premiums $P$ and risk reserve $U$. Inflation can be treated separately, as we discussed in our paper (1978), hence it can be omitted in this connection, i.e. as a working hypothesis the monetary value is assumed to be constant.

Strategy 2 consists of an assumption that company $C_{1}$ reduces its premiums by $15 \%$ in one year $t=1$ and the other companies do not react to it, i.e. their reductions are continually $=0$. For $t>1$ all companies again have joint rates $\left(\pi_{i}(t)=0\right)$. We see from fig. 4 , how company 1 gains an increase in the volume of premiums whereas the competitors suffer a loss of premium incomes and in addition a small loss of profit, i.e. both $P_{i}(5)$ and $U_{i}(5)$ for $i=2,3,4$ are somewhat smaller for strategy 2 than they were for strategy 1.

Deviating from the general practice in game theories we do not take maximising profit as a final objective of the company. Instead we assume here and in the following that company $\mathrm{C}_{1}$ has an ambition to become the largest company in the market and surpass company $\mathrm{C}_{2}$, which at the initial time point $t=0$ is the largest. To this end the company experiments with different competitive reductions $\pi_{1}(1)$, which are applied for one year and then removed. The rest of the market does not take any counteractive measures (fig. 5). Because it is crucial how much the companies' resources can stand in reductions, an indicator for security, the probability of ruin, is introduced (cf. the 


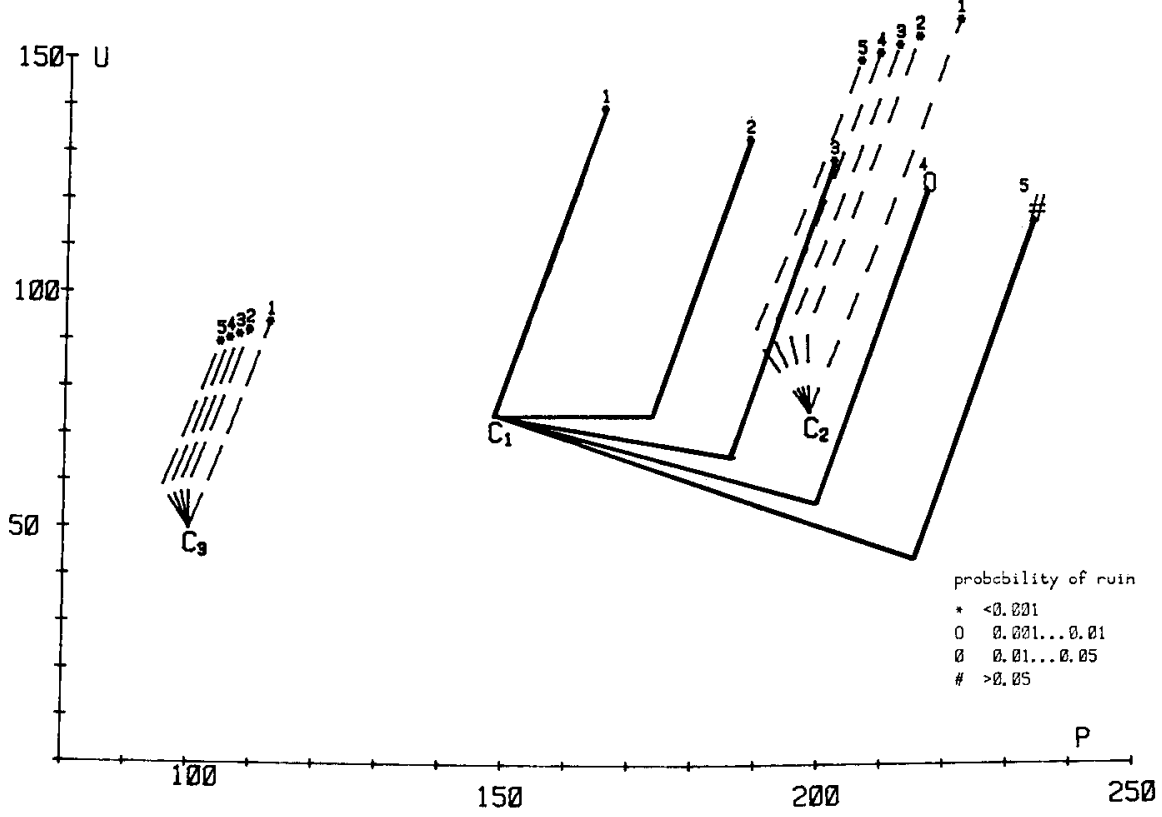

Fig. 5. Strategies of company $C_{1}$. The other companies do not take any counteractive measures.

author's paper, 1978). This is indicated by symbols in fig. 5 and in the following figures as it is shown in the right-hand corner of the picture. The reductions $\pi_{1}(1)$ for different strategies are as follows:

$\begin{array}{ll}\text { Strategy } 1 & \pi=0 \\ \text { Strategy } 2 & \pi=0.1 \\ \text { Strategy } 3 & \pi=0.15 \\ \text { Strategy } 4 & \pi=0.20 \\ \text { Strategy } 5 & \pi=0.25\end{array}$

The results are given in fig. 5 , where only companies $C_{1}, C_{2}$ and $C_{3}$ are noted. The probability of ruin for strategy 4 already begins to be alarming and for strategy 5 it is no longer acceptable. Hence it seems that strategy 3 is an acceptable choice.

Fig. 5 involves cases where the other companies do not take any counteractive measures. The analysis must be continued by studying different combinations of counteractions. That is done in fig. 6 .

Strategy 1 is again neutral as in previous pictures, and strategy 2 is again the same as that in fig. 4, i.e. in the first year only company $C_{1}$ has reduction $\pi_{1}(1)=0.15$ and the others have none. In strategy 3 all other companies respond to a premium reduction by making the very same reduction $\pi_{i}(2)=$ 
15

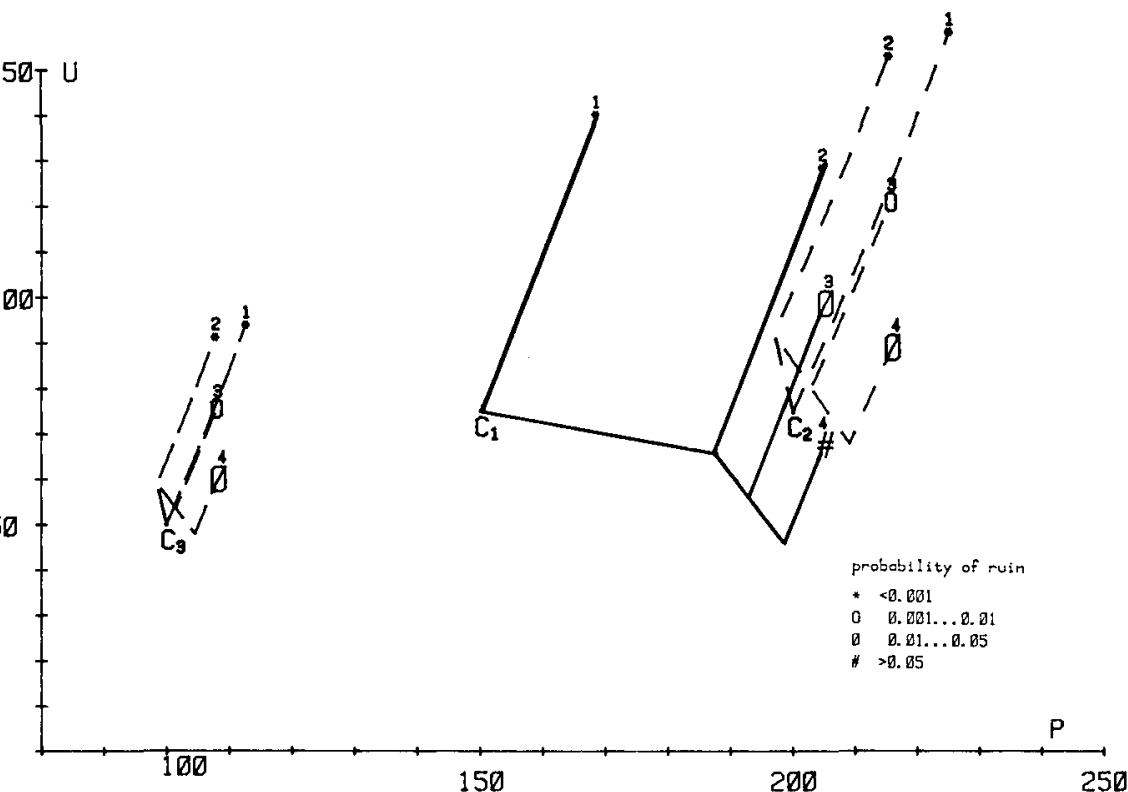

Fig. 6. Actions and counteractions.

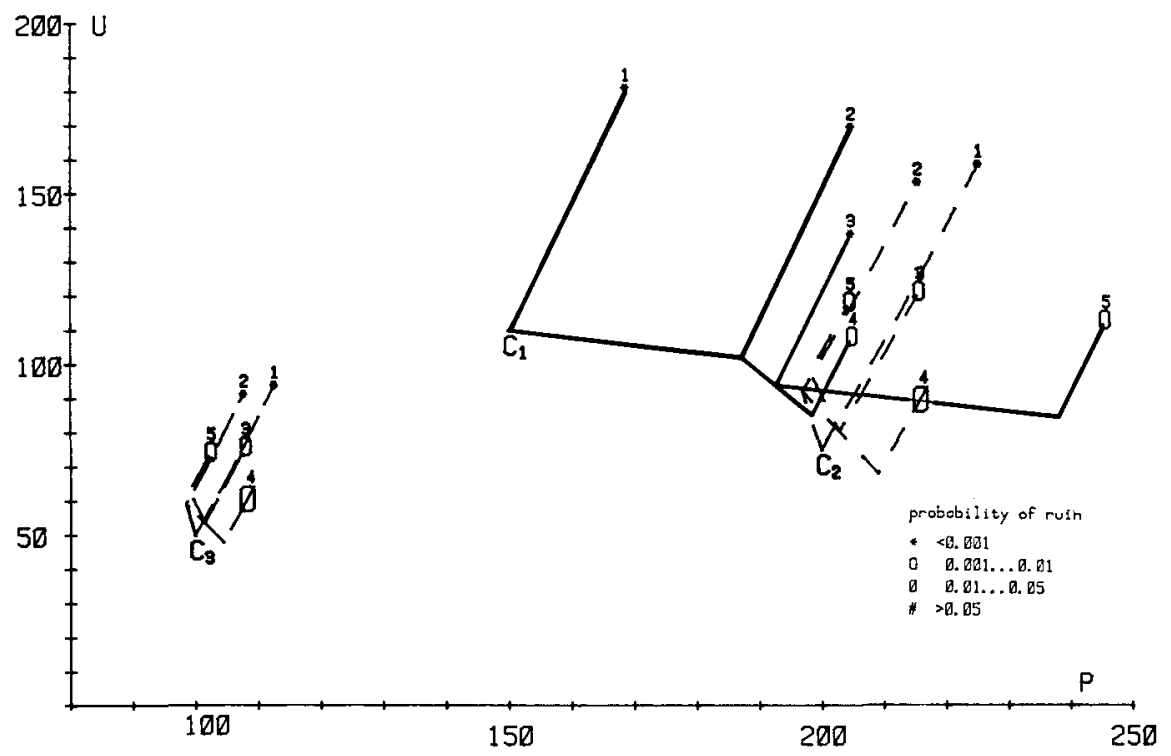

Fig. 7. Actions and counteractions; $U_{1}(0)=110$. 
$0.15(i=1,2,3)$; hence all companies apply the same reduction in year $t=2$. The result is, of course, a loss for all of them. It is interesting to observe that company $\mathrm{C}_{1}$, due to losses, is already approaching a risky state, and more seriously than its competitors, as is shown by the symbols.

Strategy 4 assumes that the joint reduction will be continued for another year $t=3$, but after that all companies will discontinue reductions. We see that the strategy puts company $C_{1}$ itself in difficulty, causing more serious losses for it than for its competitors.

We now present, as a further example, the same series of strategies but now assume that company $C_{1}$ has more initial risk reserves than it had in the preceding cases. Let $U_{1}(1)=110$ million units, whereas in the preceding cases it was only 75. The very same strategies, 1-4, are now applied again (fig. 7). The better initial resources of company $C_{1}$ obviously first put a squeeze on the main competitors $C_{2}$ and $C_{3}$. If the objective of company $C_{1}$ is rootless growth, it can probably make use of its strong state (the relatively large risk reserve) for winning market shares from other companies, because these obviously cannot afford effective counteractions over a long time without losing their security. Hence we have still continued with a strategy alternative 5 where the other companies are compelled-for the sake of their increased losses-to remove their reductions for $t=2$ whereas $C_{1}$ continues with them. Hence this strategy matrix is

$$
\text { Strategy 5: } \quad\left(\pi_{i}(t)\right)=\left(\begin{array}{lllll}
0.15 & 0.15 & 0.15 & 0 & 0 \\
0 & 0.15 & 0 & 0 & 0 \\
0 & 0.15 & 0 & 0 & 0 \\
0 & 0.15 & 0 & 0 & 0
\end{array}\right)
$$

We see how, as expected, $C_{1}$ reaches its goal, to be the largest in the market!

Finally we have experimented with a formula of elastic markets attaching another multiplicative factor $(1-\bar{\pi})-p^{\prime}$ to $(1)$. Hence an average reduction of rates $\bar{\pi}$ increases the total sum $P(t)$ of premiums by elasticity $p^{\prime}$. We repeated the computations of fig. 4 . The results are given in fig. 8 .

Strategy 1 was again neutral $(\pi)=0, p=1.5$ and $p^{\prime}=0$. For strategies 2,3 and $4 \pi_{1}(1)=0.1$ and all other $\pi_{i}(t)=0$. In case $2 p^{\prime}=0$, in case $3 p^{\prime}=0.5$ and in case $4=1.0$. If $p=p^{\prime}=1.5$ then $P$ and $U$ of companies 2,3 and 4 obtain approximately the same values as in case 1, i.e. the action of one company has no influence upon any other company. The market is perfectly elastic.

A further development of the situation obviously would lead us to wellknown problems of the theory of $n$-person games in an oligopolistic market, such as possible collutions, equilibrium, etc. (cf. Friedman (1977)). Obviously the exponential sales response function (1) must also be amended and corrected according to accumulated experience if the competitive situation 


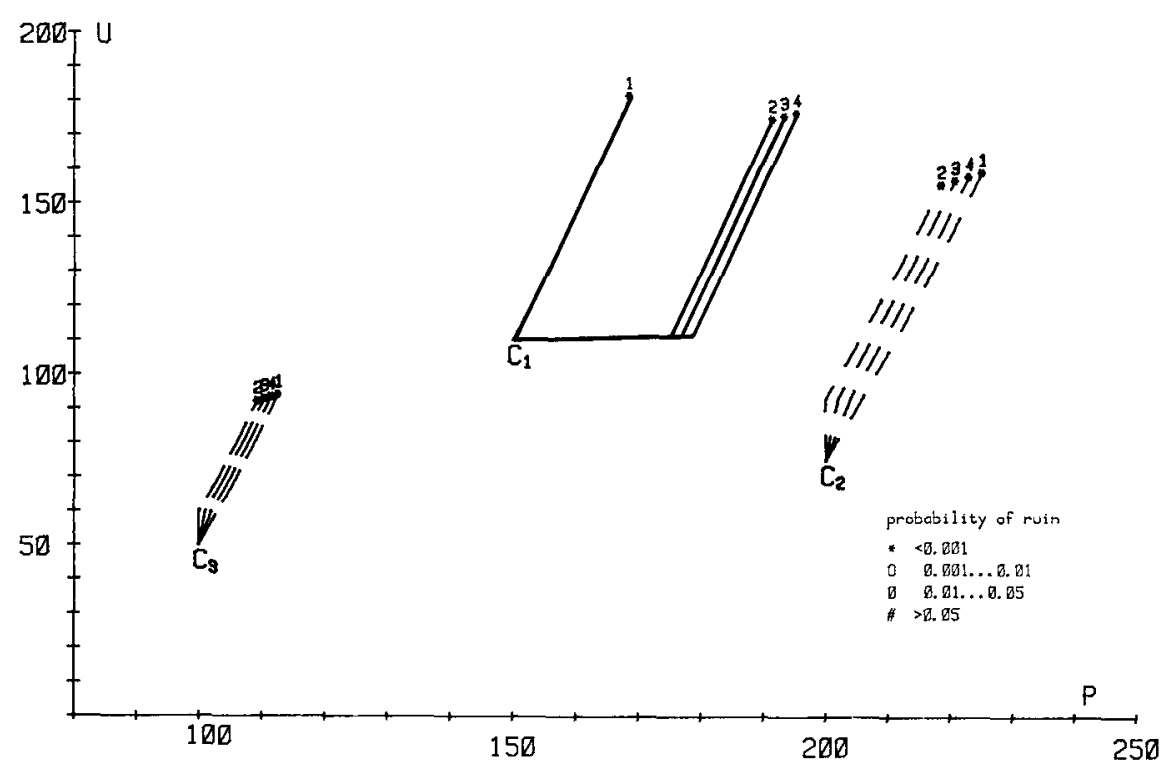

Fig. 8. Elastic market reactions.

continues for several years. Considerations like this are, however, already beyond the scope of this paper, which set out only to demonstrate how dynamic programming can be incorporated in the analysis of competitive strategies.

\section{DISCUSSION}

The idea outlined above can probably help in an estimation of the consequences of competitive measures and counteractions better than if this were done only using rules of thumb. One special merit of stochastic-dynamic programming is that it is able to give at least an approximation for the ruin probability, i.e. an estimation of the security.

Another merit of dynamic programming is its flexibility. Thanks to the simulation technique it is also able to operate rather complicated models without needing to narrow down the assumptions, as is often the case when other approaches are used. It is also possible to treat models providing multivariable utilities, in our example profit $(=U)$ and market share $(=P)$, whereas the conventional game theory mostly operates using only single variable utilities (profit). On the cther hand, it seems to be difficult to obtain elegant formulae for optimal strategies, equilibrium conditions, etc. as only data in tabular form or graphs can be obtained.

Probably "a play" by means of different strategies can help provide a better understanding of the structure and features of different alternatives of eventual policies. When the model is programmed for a computor the numerous alternatives can be plotted, as was illustrated in the preceding figures. The same 
program can also be used for playing a business game, where teams of participants are simultaneously "managing" companies $C_{1}, C_{2} \ldots$

REFERENCES

Bellman, R. and R. Kalaba (1965). Dynamic programming and modern control theory. Academic Press, New York and London.

Friedman, J. W. (1977). Oligopoly and the theory of games. North Holland Publishing Company, Amsterdam, New York and Oxford.

KOTLER, P. (1975). Marketing decision making, a model building approach. Holt, Rinehart and Winston, New York.

Pentikäinen, T. (1975). A model of stochastic-dynamic prognosis. Scandinavian Actuarial Journal, 3 29-53.

Pentikätnen, 'T. (1976). Stochastic-Dynamic prognosis. Transactions of the Congress of Actuaries, Tokyo, 659-67o.

Pentikäinen, T. (1978). A solvency testing model building approach for business planning, Scandinavian Actuarial Journal, 6 19-37. 